\title{
Preparação para a morte: investigação fenomenológica sobre a experiência de idosos longevos
}

\author{
Gabriela Machado Giberti* (1) \\ Helena Rinaldi Rosa
}

Universidade de São Paulo, Instituto de Psicologia. São Paulo, SP, Brasil

\begin{abstract}
Resumo: $O$ envelhecimento populacional é um fenômeno mundial que ganhou destaque nas últimas décadas. Nesse contexto, a morte aparece como questão difícil, pois se trata de um tema tabu na cultura ocidental. À luz da fenomenologia existencial, este projeto objetivou compreender a experiência de idosos longevos que consideram que se prepararam para a morte. Constataram-se diversas iniciativas permeando questões financeiras, emocionais, sociais, corporais, materiais e até espirituais. O sentido dessas preparações se desvelou como um cuidar da vida, pois se mostraram tentativas de garantir a melhor qualidade na existência, seja em relação à vida do próprio idoso até sua morte, seja de quem permanece vivo até e depois da morte do idoso, como familiares e amigos. Assim, fica evidente que "a única certeza da morte é a vida", pois entrar em contato com a finitude viabiliza o encontro das possibilidades de vida dignas de serem vividas.
\end{abstract}

Palavras-chave: envelhecimento, morte, atitude diante da morte, fenomenologia, hermenêutica.

\section{Introdução}

A transição demográfica, ou seja, a dinâmica do crescimento populacional é um fenômeno social importante que vem ganhando destaque nas últimas décadas. Esse acontecimento retrata uma alteração no perfil mundial: cada vez mais existem menos crianças e jovens, ao passo que a população com idades mais avançadas aumenta continuamente (World Health Organization, 2015). É possível observar essa tendência nas estatísticas brasileiras, dado que, a partir de meados dos anos 1980, as transformações do padrão etário do Brasil ficaram mais evidentes (Instituto Brasileiro de Geografia e Estatística, 2008).

O segmento de pessoas com 80 anos ou mais se configura como o grupo de idade com o maior e mais acelerado crescimento (Instituto Brasileiro de Geografia e Estatística, 2008). Idosos com mais de 80 anos podem ser denominados como "longevos" (Brasil, 2006). Perante o aumento exponencial dessa faixa-etária, Lourenço et al. (2012) reforçam a importância de explorar o perfil dessa população para aprimorar a assistência a tais indivíduos. Lima e Menezes (2011) constataram escassez de publicações que abordam idosos longevos como tema central, evidenciando a necessidade de investir em pesquisas científicas com essa população.

O tempo do envelhecimento está ligado à percepção da finitude, pois há o estreitamento do horizonte de futuro e a convicção de que a maior parte da vida já foi vivida, ou seja, para o velho, a proximidade da morte

* Endereço para correspondência: gabrielagiberti@gmail.com não é apenas uma possibilidade, mas se configura como certeza (Barbieri, Goldfarb, Gotter, \& Peixeiro, 2009). A velhice não tem início visivelmente definido, mas tem um fim claramente estabelecido: a morte (Kovács, 1992).

A fenomenologia coloca em questão a naturalidade do envelhecer e da morte, pois, de acordo com Giberti (2018), "rompe com a visão do homem natural que, igual a uma árvore, possui uma semente que brota, cresce, tem as flores, os frutos, envelhece e morre" (p. 33). Embora todos passem por esse processo vital que é "natural", no sentido de que ninguém escapa do envelhecimento e da morte, o ser humano compreende esse processo (Heidegger, 1927/2012) e, por isso, o envelhecer e a finitude não são vivenciados de uma única forma, cada pessoa os entende de maneira singular.

A história do homem revela diversas representações sobre a morte, diferentes atitudes perante o morrer e inúmeras significações em relação à compreensão do indivíduo sobre sua própria finitude (Ariès, 1977/2012). Com o desenvolvimento da indústria, da técnica e da medicina, há uma inversão na imagem da morte e ela vai se tornando selvagem (Ariès, 1977/1989), no sentido de não ser um tema civilizado.

Ao ponderar sobre a modernidade, Heidegger (1953/2002) denomina o horizonte histórico contemporâneo como a "era da técnica". Trata-se de uma época pautada na crença do domínio do homem sobre a natureza (Feijoo \& Dhein, 2014), mas é impossível conter a morte: por isso a modernidade a entende como fracasso. A morte é interdita e, assim como a sexualidade, configura-se como tabu, sendo que a atitude predominante perante a morte é o medo (Combinato \& Queiroz, 2006). 
Entretanto a morte é a única certeza da vida (Andrade, 2012). A morte é um problema dos vivos, que sabem que morrerão e que a qualquer momento podem morrer, por isso é possível tomar precauções e providências como indivíduos e como seres pertencentes a grupos (Elias, 1982/2001).

Kübler-Ross (1981/2016) defende que os seres humanos deveriam ter o hábito de pensar na morte e no morrer antes que se defrontassem com eles na vida, assim como deveriam ter o costume de conversar sobre isso como parte intrínseca da vida. Contudo as pessoas tendem a não encarar abertamente sua finitude ou só ocasionalmente e com temor lançam um olhar sobre a possibilidade de sua própria morte, sendo uma dessas ocasiões quando há consciência de que sua vida está ameaçada por uma doença (Kübler-Ross, 1981/2016). Considera-se que a idade avançada, como no caso dos idosos longevos, também seja um fator que anuncia a proximidade da morte.

A era da técnica tende a tornar nossas vivências cada vez mais absorvidas, planificadas e distantes de um sentido autêntico e livre de ser (Casanova, 2006). Assim, para alguém conseguir, de forma autônoma, refletir sobre a própria existência e decidir um projeto de vida que inclua um projeto de morte, é necessário quebrar um tabu social, rever sentidos sedimentados de mundo e enfrentar, minimamente, a angústia fundamental perante a finitude. Fica claro, então, que essa tarefa não é fácil no mundo contemporâneo.

\section{Objetivos}

Visou-se compreender os desdobramentos e os sentidos da experiência de idosos longevos, residentes da cidade de São Paulo, que consideram que se prepararam para a própria morte.

\section{Método}

Trata-se de pesquisa qualitativa fundamentada no pensamento da fenomenologia existencial que adotou a entrevista reflexiva (Szymanski, 2004) como método compatível com tal referencial. Esse método tem possibilidade dialógica, pois oferece ao participante espaço de reflexão sobre o tema em questão. Essa modalidade de entrevista desencadeia um processo de intervenção realizado pelo próprio pesquisador, possibilitando ao participante um movimento de articulação de novos sentidos (Szymanski, 2004).

Outro aspecto essencial da entrevista reflexiva é que não há um roteiro fechado a ser seguido, sendo a entrevista norteada pela clareza do pesquisador sobre os objetivos de seu trabalho. Há a elaboração de uma questão desencadeadora que se configura como ponto de partida para o início da fala do participante, focalizando o ponto que se quer estudar e, ao mesmo tempo, ampliando o suficiente para que ele escolha por onde quer começar
(Szymanski, 2004). A pergunta disparadora utilizada foi: de que maneira o sr./sra. considera que se preparou e/ou está se preparando para a morte?

O projeto de pesquisa foi submetido ao Comitê de Ética do Instituto de Psicologia da Universidade São Paulo e conta com aprovação sob parecer $n^{\circ} 1.828 .405$ e CAAE $\mathrm{n}^{\circ}$ 60889516.2.0000.5561. Foram convidados idosos com mais de 80 anos, de ambos os sexos, que consideram que estão se preparando ou já se prepararam de alguma maneira para a própria morte e que se dispuseram a conversar sobre esse assunto. Com essa idade, o idoso tem uma perspectiva de futuro encurtada, podendo favorecer o contato com a temática da finitude. Não foram convidados idosos com comprometimento cognitivo, pois entende-se que essa condição pode alterar a fidedignidade das respostas.

Esse trabalho não busca generalizações, pois se entende que a experiência é única e singular (Minayo, 2017), assim, foram entrevistados três idosos visando ao aprofundamento da experiência de cada um. Portanto a pesquisa em fenomenologia contribui para ampliar possibilidades existenciais, no sentido de mostrar o que foi possível, para cada entrevistado, em relação à preparação para a própria morte no mundo contemporâneo.

Tendo em vista que o objetivo desta pesquisa é interrogar sobre o "sentido", a análise das informações reunidas foi encaminhada tendo como fundamento o método desconstrutivo-construtivo, inspirado no que Critelli (2006) nomeia como Analítica do Sentido. O trabalho analítico fenomenológico pretende tornar visível a trama de significados que cada participante construiu no processo da entrevista reflexiva. Sodelli (2006) sintetiza o processo de análise em três momentos: apresentação dos focos de análise e sua respectiva compreensão; texto descritivo/interpretativo, que busca compreender o modo de ser de cada entrevistado; e texto analítico, que procura entender qual é o sentido, para cada pessoa, da preparação para sua própria finitude.

\section{Resultados}

Foram realizadas três entrevistas nas casas dos participantes. Importante esclarecer que todos os nomes utilizados para eles são fictícios, a fim de preservar sua identidade.

Marina nasceu em Salvador, Bahia. Tem 82 anos, é analfabeta e viúva. Tem quatro filhos, sendo dois homens e duas mulheres, oito netos(as) e sete bisnetos(as). Mudou-se para São Paulo em 1960, pois não queria mais ficar com o marido. Mora com uma neta e uma bisneta. Trabalhou em um hospital infantil como auxiliar de serviços gerais e, atualmente, é aposentada.

Cristina é baiana, tem 84 anos, conta com ensino superior completo e é divorciada. Tem um filho e uma filha biológicos, além de seis netos, mas também criou mais 24 crianças. Mudou-se para São Paulo em 1988 para acompanhar a filha e os netos. Mora sozinha, é economista 
aposentada, mas ajuda a organizar a contabilidade da clínica de fisioterapia de sua filha.

Arthur é húngaro, tem 94 anos, conta com ensino médio completo, é divorciado e viúvo. Tem um filho e cinco netos. É judeu, mudou-se para o Brasil aos 27 anos para fugir do Holocausto. Empreendedor aposentado, Arthur mora sozinho, mas tem acompanhamento constante de cuidadoras.

O primeiro aspecto importante a ser destacado é que todos os entrevistados apresentaram, de alguma forma, uma concepção de "morte ideal". Todos convergem no desejo de ter uma morte tranquila, rápida e sem sofrimento.

Marina apresenta a especificidade de querer morrer em casa, pois compreende o ambiente cirúrgicohospitalar como ameaçador de sua expressão dos sentimentos, dizendo: "gostaria de ter uma morte ... em casa. Eu não gostaria de morrer em uma mesa de cirurgia! . . você toma anestesia, você quer falar alguma coisa, mas não pode falar". Destaca-se que Marina tomou a iniciativa de expor essa preferência para sua médica de referência, mas conta que a profissional não gosta de falar do tema da finitude. Diz: "Eu mesmo que puxo o assunto com ela! Ela não gosta, mas eu que puxo o assunto".

Cristina, por sua vez, faz uma articulação com suas crenças religiosas ao dizer "eu só quero que, quando eu for, seja Deus que leve ... eu tenho pena quando eu vejo uma pessoa morrer antes da hora, de alguém tirar a vida, de matar, . . um acidente ..., porque é interromper a vida da pessoa". Demonstra, assim, a importância da percepção de que a vida foi vivida por inteiro, como se houvesse um ciclo que tem começo, meio e fim. A entrevistada comenta que "Se Deus me levar, eu quero que seja em um sopro, como quem apaga uma vela", mas aponta que nunca conversou sobre morte com seus médicos, deixando a questão ser encaminhada na esfera espiritual.

Já Arthur demonstra preocupação com o prolongamento desnecessário da vida por meio dos procedimentos médicos. Ele diz "Você sabe o que é o testamento vital? Eu falei para ela que, chegando a hora, não me deixe sofrer, não esticar a minha vida, nada, me deixa ir embora calmamente". O entrevistado esclarece que sempre colocou em pauta o assunto sobre sua morte com a médica, mas aponta que, depois de tomar conhecimento sobre o testamento vital, sente que suas vontades em relação às condutas médicas ao final de sua vida puderam ser oficializadas.

Foram destacadas, também, preferências relacionadas aos rituais fúnebres. Marina comprou um túmulo antes mesmo de se aposentar, a partir da compreensão de que, "quando a gente morre, dá muito trabalho para enterrar". Essa iniciativa indica preocupação e atenção com sua morte, que é ainda mais reforçada a partir do esforço financeiro feito para conseguir concretizar a compra, pois "não tinha nem dinheiro! A vizinha que me emprestou para eu poder pagar a prestação".

Cristina, por outro lado, deseja ser cremada: "quero que as minhas cinzas sejam soltas no vento. Onde caiu, caiu. Porque eu tenho certeza que ali, onde cair, vai nascer o bem". Fica clara a expectativa de que algo nasça a partir das suas cinzas, indicando um desejo de continuidade, de que sua morte não seja o fim absoluto, mas a origem de algo novo e bom. A participante expõe que seus familiares estão cientes dessa preferência.

Importante ressaltar que, a partir dos 80 anos, Cristina fez uma preparação financeira, aplicando dinheiro em uma conta que sua filha tem acesso, para que seja utilizado para financiar seus rituais de morte. Além disso, a entrevistada elegeu um neto para transmitir a forma como ela lida com sua vida financeira, além de informá-lo sobre contas de bancos e senhas de acesso. Cristina também deixa seu histórico de exames clínicos disponíveis em sua casa, caso haja alguma intercorrência, na qual a família ou uma equipe médica precise ter acesso ao seu histórico clínico. Aponta: "a minha família . . . está sabendo de tudo isso. Está tudo na mão deles.... Todos sabem onde está tudo".

Outro tema que apareceu como desencadeador de preocupação foi relacionado às questões patrimoniais. Arthur discorre que não se preocupou em fazer um testamento por ter um filho único, ou seja, um único herdeiro. Contudo diz ter feito doações para instituições filantrópicas ao longo da vida e menciona: "deixei por escrito ... uma relação para o meu filho para premiar ..., na maioria é dinheiro . . ., as minhas cuidadoras que são muito boas". Ele demonstrou insegurança sobre se o filho respeitaria essa vontade, mas não o suficiente para fazer essas premiações em vida e garantir que fossem realizadas.

Marina, por sua vez, narrou: "eu só tenho essa casinha aqui. ... Ai falei com a advogada, para ela... deixar no nome dessa minha neta que eu criei e que mora aqui comigo. . . . Minha preocupação é com essa casa. Porque os papéis ainda não estão prontos". Ela também estava insegura em relação ao filho caçula, se ele aceitaria essa decisão e se teria respaldo da lei para transmitir seu patrimônio para a neta, e não para os filhos.

Um elemento essencial narrado por Marina é quanto aos relacionamentos sociais. A partir da notícia de que poderia morrer de um dia para o outro devido a um diagnóstico de aneurisma, providenciou uma viagem a Salvador para se despedir de seus familiares. Além disso, ela diz conversar frequentemente sobre sua morte com a família, especialmente com seus filhos, com o intuito de conscientizá-los e prepará-los para o fim de sua existência. Entretanto nota-se uma resistência e dificuldade por parte dos familiares em aderirem à iniciativa de Marina. "Ninguém quer falar de morte. Eu sempre falo aqui para os meus filhos ..., e eles: mãe para como isso! E eu digo: meu povo, eu não posso parar com isso! É coisa da vida, gente!" 
No discurso da Cristina e do Arthur, a questão do legado apareceu, de diferentes formas, como um aspecto digno de ser cuidado. Cristina conta:

Já preparei enxoval para todos os bisnetos, ... porque eu posso ir antes da chegada dos bisnetos. ... os pais vão dizer: isso aí foi a sua bisa que fez! . . I Isso aí é que é bom, não é? Por que você já pensou, passar pela vida e ninguém se lembrar de você? ... Isso é a continuidade da vida. Essa lembrança não apaga, ela continua.

Arthur, por sua vez, diz que:

o que eu queria, mas nunca vou saber, que pensem em mim não com raiva, desprezo, qualquer coisa assim. Que eu deixe uma imagem positiva. . . Aliás, a minha religião é: o que você não deseja para si não faça para outro... em toda a minha vida, eu só pensei nos outros.

Entretanto, deixa claro que nunca vai saber qual é a visão dos outros a seu respeito, ou seja, não toma iniciativa para explorar tais concepções, restando-lhe torcer para que sua história seja contada de forma a ressaltar suas qualidades.

Acerca da espiritualidade, Arthur comenta que nenhuma certeza religiosa faz sentido para ele e se define como agnóstico, ou seja, identifica-se como ignorante, pois não sabe e não tem a pretensão de desvendar o mistério sobre o que acontece depois que se morre. Ele diz: "eu não quero inventar respostas para o que eu não sel", e se incomoda com a tentativa constante das religiões de explicar o inexplicável, de dar respostas àquilo que não se tem garantia, especialmente no que se refere à questão da morte.

Por outro lado, Marina e Cristina acreditam em vida após a morte e demonstram que a confiança de que há uma continuidade após o fim do corpo biológico proporciona o sentimento de tranquilidade com a finitude. A partir dessa crença, Cristina expõe a preocupação em não deixar dívidas nessa encarnação como um possível facilitador de uma próxima vida tranquila. Ela diz: "não deixo dívidas, vou tranquila, ... porque eu sei que vou seguir outro estágio, porque eu acredito na reencarnação".

Marina e Cristina comentaram que não têm medo da morte, mas Arthur foi o único entrevistado que enuncia uma preparação da ordem do pensar e do sentir: como ele vê a morte, o que ele acha sobre a finitude e o que ele sente perante essa percepção. Expõe que começou a se preparar para a morte desde criança, no sentido de pensar sobre o que é a morte. A visão da morte como algo incontrolável e incerto fez Arthur sentir medo da finitude por muito tempo. Entretanto narra: "a vida inteira eu tinha certo medo da morte, eé interessante: agora, depois de velho, isso desapareceu totalmente. . . . eu começo a apropriar o pensamento de que a morte é um repouso".

Por fim, os três entrevistados indicaram iniciativas de cuidado com a própria vida até sua morte, sendo que todos valorizaram a convivência com a família e amigos como aspecto relevante do cotidiano. Cristina, especialmente, destacou a importância de se manter ativa, produzindo suas costuras e ajudando a filha no trabalho. Marina, por outro lado, ressaltou que evita se expor a situações nas quais depende de terceiros, visando a preservar sua independência e se afastar do incômodo de sentir que está atrapalhando alguém. Arthur ressalta o cuidado com o corpo como algo essencial para ele. Logo faz consultas médicas a cada dois meses, além de fisioterapia, e investe em recursos que lhe deixam mais funcional, como a aquisição de uma cadeira de rodas para facilitar sua circulação e de uma tela grande de computador que facilite a leitura.

\section{Análise e discussão}

Considerando que a questão da morte seja um tabu na cultura ocidental (Ariès, 1977/2012), é importante ressaltar que nenhum dos três entrevistados demonstrou resistência e/ou dificuldade em discorrer sobre o assunto. Todos sabiam do objetivo da pesquisa e, uma vez que aceitaram o convite em participar, já tinham abertura à temática. Trata-se de um tema que frequentemente provoca angústia. Por isso é compreensível ter opiniões e sensações contraditórias sobre essa questão e, também, é comum a criação de verdades sobre o tema na tentativa de controle perante a fragilidade da vida e a imprevisibilidade da morte.

Podem-se identificar aspectos relacionados aos receios e preferências sobre o morrer no discurso dos três entrevistados: todos desejam uma morte rápida e sem sofrimento. Marina e Arthur, especialmente, apontam críticas à medicina contemporânea, uma vez que ela quer morrer em casa e ele se preocupa com o prolongamento desnecessário de sua vida. Os avanços tecnológicos na medicina contribuíram para salvar mais vidas, revolucionar a qualidade de vida e a longevidade humana. Entretanto inaugura-se uma discussão bioética importante quando se busca prolongar uma existência na qual a morte já é presente, muitas vezes sem considerar a qualidade de vida em questão, configurando uma situação de distanásia (Nunes \& Anjos, 2014). Segundo Pessini (2007), distanásia significa o prolongamento exagerado do processo de morte por meio de tratamentos fúteis que visam apenas a evitar a morte a qualquer custo.

A tendência moderna de preservar a vida de qualquer maneira, segundo Kovács (2003a), gera "um dos maiores temores do ser humano na atualidade, que é o de ter a sua vida mantida às custas de muito sofrimento, solitário numa UTI, ou quarto de hospital, tendo por companhia apenas tubos e máquinas" (p. 115). $\mathrm{O}$ desejo por uma morte rápida e sem sofrimento, 
de preferência em ambiente familiar, ressurge com intensidade (Kovács, 2014).

Dignidade é morrer com afirmação de valores e crenças essenciais na vida da pessoa (Kovács, 2003b). Para viabilizar o morrer com dignidade, é preciso falar sobre a finitude, contudo é comum os profissionais da saúde não terem preparo para lidar com os conflitos ligados ao envelhecimento e à morte (Franco, 2007). Foi possível notar essa dificuldade contemporânea nos médicos que assistem a Marina e a Cristina, pois, apesar do vínculo antigo, eles não tomaram iniciativa de colocar em pauta a questão da finitude. Marina, entretanto, quebrou o silêncio e insistiu em falar de suas preferências com sua profissional, como seu desejo de morrer em casa.

Kübler-Ross (1981/2016) aponta a necessidade dos profissionais da saúde se atentarem às reações e atitudes no trabalho ao encararem a morte. A autora diz que se esse tema é um grande problema na vida particular do profissional: não será possível acolher o sofrimento e ajudar o paciente que vivencia o contato com a finitude.

No caso de Arthur, o diálogo sobre a morte aparece mais espontaneamente com sua médica. Inclusive, ele introduz um elemento importante relacionado às diretivas antecipadas de vontade (DAV). Seus desejos de não ter a vida futilmente prolongada em contexto hospitalar e de não ter uma morte com sofrimento puderam ser oficializados por meio do testamento vital. Trata-se de documento facultativo sobre o conjunto de desejos, prévia e expressamente manifestados pelo paciente a respeito de tratamentos que quer ou não receber no momento em que estiver incapacitado de expressar, livre e autonomamente, sua vontade (Conselho Federal de Medicina, 2012).

Diante da flagrante perda de autonomia contemporânea que afasta as pessoas do seu processo de morrer, consideram-se as DAVs instrumentos facilitadores da morte digna (Kovács, 2014). As DAVs contribuem para evitar processos distanásicos, favorecendo a ortotanásia, ou seja, o não prolongamento artificial do processo de morte além do que seria o natural (Junges, Cremonese, Oliveira, Souza, \& Backes, 2010).

É importante discutir também sobre o diagnóstico de uma doença que ameaça a vida. No caso de Marina, o aneurisma escancara a proximidade da morte, pois é uma "bomba-relógio", uma vez que vive diariamente com a certeza de poder morrer a qualquer momento. Todos os seres humanos vivem essa iminência, afinal, para morrer basta estar vivo - inclusive a condição de ser longevo também é um anúncio de que o futuro não é tão extenso. Entretanto é rotineiro o esquecimento dessa condição fundamental e, por isso, um diagnóstico que anuncia a morte rompe com a ilusória segurança existencial de imunidade ao fim da vida.

O diagnóstico trouxe para Marina a prioridade de se despedir das pessoas que lhe são caras, reforçando a importância desses vínculos em sua vida, por meio de uma festa de despedida. Como é, na realidade brasileira, a ideia de festejar a morte? Em uma cultura que tenta combater a morte e que se assusta perante ela, esse tipo de festejo parece não ser uma possibilidade familiar. Outras culturas lidam de maneiras diferentes com a morte, como o caso do Dia dos Mortos, no México, que consiste em uma forma de homenagear pessoas que já faleceram. Trata-se de celebração que utiliza representações da morte com humor, por exemplo, por meio de gravuras que interpretam a vida cotidiana com caveiras atuando como pessoas comuns (Villasenor \& Concone, 2012).

A representação, os sentidos e significados acerca da morte e o que se sente perante ela são distintos dependendo da história de vida e das experiências individuais (Andrade, 2012). Os três entrevistados apontaram não temer a morte, mas o que isso quer dizer para cada um é singular.

Arthur foi o único que considerou uma preparação para a morte da ordem do sentir e do pensar. Ele se empenhou durante sua vida para desmistificar essa temática para perder o medo e sentir serenidade diante da ideia da morte quando, já idoso, ela passa a significar um repouso. A finitude não se torna mais terrível como na sua infância, em que a vida inteira ainda tinha de ser vivida e a morte seria uma ameaça à promessa de uma vida inteira.

Nota-se que o medo da morte de Arthur estava intimamente relacionado com sua visão sobre a finitude, pois, a partir da alteração na visão sobre a morte, o medo dela também desaparece. Fica claro que a visão e o sentimento perante a vida e a morte são dinâmicos, de acordo com a temporalidade. Ou seja, a relação com essa temática não é estanque e definitiva, podendo ser trabalhada na direção de buscar uma relação com a morte que envolve aceitação e ausência de sofrimento.

Ressalta-se, também, a questão da espiritualidade e sua influência no modo como as pessoas encaram a finitude. Marina e Cristina acreditam que a morte não é um fim absoluto, pois creem que existe vida após a morte. A confiança de que há uma continuidade após o fim do corpo biológico as ajuda a aceitar a própria finitude e a lidar com a angústia que essa percepção provoca. Para Martins (2007), o conforto que a fé proporciona vai além dos limites da racionalidade e da ciência, pois "morte, então, nessa perspectiva, não é perda, mas um ganho, pois o ser ultrapassa o limite humano dessa existência finita para ter um encontro com o infinito" (p. 177).

A espiritualidade relacionada à saúde tem sido cada vez mais investigada e as evidências apontam para relação positiva entre envolvimento religioso e saúde mental (Moreira-Almeida, Lotufo-Neto, \& Koenig, 2006). A fé tem função importante para o ser humano diante do desafio da própria morte, pois favorece um final de vida mais tranquilo (Martins, 2007). O comportamento religioso pode contribuir à adesão ao tratamento, redução do estresse e da ansiedade, melhoria da qualidade de vida e busca de significado para a situação atual (Fornazari \& Ferreira, 2010). 
Fica evidente a importância de se considerar os aspectos religiosos e espirituais ao acolher uma pessoa que tem como questão a finitude, para que cada um seja respeitado em sua singularidade, suas crenças e seus valores (Fornazari \& Ferreira, 2010). Esses elementos influenciam na visão de vida e de morte, facilitando ou não o enfrentamento do fim da vida.

Destaca-se mais uma forma de preparação para a morte que permeou o discurso dos três entrevistados: a questão financeira e patrimonial. Diferentes recursos foram utilizados na tentativa de garantir que o encaminhamento do patrimônio após a morte seguirá seus desejos pessoais: contratação de advogada para fazer testamento, escolha de um parente representante ou até mesmo a transmissão dos bens em vida.

No que se refere à transmissão patrimonial, há o atravessamento das leis e das vontades de quem sobrevive, que podem limitar e impedir que as diretrizes individuais do falecido sejam concretizadas. É essencial esclarecer que os três entrevistados não apresentam comprometimento cognitivo que interfira na autonomia de decisão sobre as diversas questões patrimoniais mencionadas. Contudo vale ressaltar que muitos idosos passam pelo processo de interdição judicial, que se configura como uma medida de proteção às pessoas que, por incapacidade física ou mental, não conseguem mais praticar sozinhas atos da vida civil e, por isso, necessitam de um curador que administre a vida civil do interditado (Crippa \& Gomes, 2014).

Coloca-se em pauta, então, a relação com a família. Como citado, os três entrevistados conversaram com seus familiares sobre aspectos relacionados à morte para informá-los, por exemplo, sobre preferências em âmbitos práticos, como as diretrizes patrimoniais e financeiras, além de orientações sobre o ritual fúnebre. Trata-se de questões que serão encaminhadas por terceiros, pois serão concretizadas após o falecimento. Essas iniciativas revelaram o sentido de tentar garantir que suas vontades sejam respeitadas depois que eles não estiverem mais vivos e são uma forma de apaziguar a angústia do descontrole absoluto perante a finitude.

Pondera-se como é, para as famílias, respeitar ou não as escolhas dos familiares relacionadas ao contexto da morte. O modo como lidarão dependerá do vínculo entre as partes e de como cada um lida com a finitude. Entretanto essa dinâmica também é atravessada pela lógica moderna de distanciamento da temática da morte, em que o espaço de diálogo sobre as preferências e limitações individuais fica comprometido (Kübler-Ross, 1981/2016).

Deve-se ressaltar que algumas iniciativas de preparação para a morte tiveram como objetivo o cuidado com a família do idoso. Destaca-se a iniciativa de Cristina de fazer uma reserva financeira com a finalidade de custear os gastos decorrentes de seu falecimento como forma de proteger sua família, evitando que eles tenham qualquer despesa com sua morte. Além disso, deixar um neto ciente sobre suas contas e senhas bancárias revela o intuito de facilitar os processos burocráticos com os quais a família lidará após sua morte.

$\mathrm{O}$ ato de Marina comprar um túmulo retrata um cuidado com sua própria morte, na direção de assegurar que ela tenha um lugar próprio para ser enterrada, mas também demonstra um cuidado com sua família. Isso porque ela tem a percepção de que enterrar alguém dá trabalho, assim esse ato traduz a intenção de preservar as pessoas que providenciarão seu enterro, poupando-os dessa demanda específica.

Marina, além de realizar as orientações mais objetivas, também demonstrou querer dialogar sobre a morte em uma direção mais reflexiva com o objetivo de conscientizar seus familiares de sua finitude e ajudá-los a se prepararem para isso. Contudo ela deparou com a resistência da família em aderir ao tema. Pergunta-se como é, para famílias, acompanhar a proximidade anunciada da morte de um parente, que pode mobilizar sentimentos das mais diversas origens, a depender da qualidade do vínculo.

Kübler-Ross (1981/2016) coloca que, quando o paciente morre, seus problemas chegam ao fim, mas permanecem os da família, uma vez que seus membros entram no trabalho de luto. Recupera-se o conceito de luto como um processo esperado em consequência do rompimento de um vínculo (Franco, 2008). A perda altera o sistema familiar, sendo que a maneira como os membros se reorganizarão dependerá da dinâmica de cada família. Destaca-se que quem faleceu permanece vivo para quem não morreu, pois a lembrança é uma forma de relação que pode contribuir na elaboração da perda e no enfrentamento do luto.

A memória sobre a pessoa que faleceu terá a tonalidade do significado que ela tinha para quem ficou vivo. Bosi (1994/2016) define que "a lembrança é a sobrevivência do passado" (p. 53). Não à toa, Cristina e Arthur demonstraram preocupação com o legado que deixarão. Ambos manifestaram querer garantir a qualidade das lembranças que as pessoas terão sobre eles: Arthur quer ser recordado como um bom ser humano ético e Cristina, como uma pessoa boa e ativa. Cristina deixa claro o medo de ser esquecida, sendo essa uma das motivações por fazer o enxoval para os futuros bisnetos, como se o material concreto falasse por si, solidificasse a autoria e carregasse parte de sua história, eternizando sua memória.

Foram diferentes os tipos de preparação para a morte apreendidos nas entrevistas. Mas, afinal, o que é se preparar? Sendo esse um verbo que conota uma ação, Houaiss e Villar (2009) trazem o significado por meio de outros verbos, como aparelhar, arrumar, premeditar, organizar e outros. Preparação nada mais é do que preparar uma ação, ou seja, há uma condição fundamental para o entendimento desse ato: a antecipação do que virá posteriormente. Não é possível experienciar a morte, mas sim antecipá-la. 
Martins (2007) aponta que é diário o convívio com a morte, mas costuma ser a morte do "outro" que está em jogo. Quando uma pessoa entra em contato com a morte por meio de terceiros ou de circunstâncias como um velório, é possível que ela seja tocada pela fragilidade e pela angústia da sua condição fundamental de ser-para-a-morte. Sobre isso, Heidegger (1927/2012) expõe que "ninguém pode tomar de um outro o seu morrer. . . . O morrer, deve assumi-lo todo Dasein cada vez por si mesmo. A morte, na medida em que 'é, é essencialmente cada vez a minha" (p. 663). A finitude de uma pessoa é uma experiência singular e intransferível.

Esse entendimento propicia a reflexão sobre a vida que é, também, "minha", e a oportunidade de apropriação da existência, no sentido de escolher viver aquilo que, individualmente, é digno de ser vivido. Pondera-se sobre a tarefa ontológica de cuidado com a existência e sobre seu caráter de indeterminação. Feijoo (2011) coloca que "cabe ao ser-aí e apenas a ele a sua tutela: é isto que a decisão antecipadora da morte revela, determinando o seu modo próprio de ser" (p. 133). Ou seja, entrar em contato com a finitude possibilita encontrar sentidos singulares para a vida. Reis (2004) reforça que "como ser-para-a-morte, abre-se para o ser humano a alternativa do ... estar própria ou impropriamente nas possibilidades existenciais. . . . No modo autêntico de ser-para-a-morte, a antecipação decidida da negatividade das possibilidades existenciais, pode acontecer a singularização da existência” (p. 67).

A partir disso, constata-se que todas as possibilidades de preparação para a morte apresentadas pelos entrevistados se relacionam, de alguma forma, com a vida. A respeito da vida do próprio idoso até sua morte, notaram-se iniciativas de investimento na melhor qualidade de vida, por exemplo, por meio da busca de maior funcionalidade, autonomia e independência, além de preparações como falar com os médicos para desenhar diretrizes de um final de vida sem dor, ou a iniciativa de se despedir de quem foi importante nessa existência. Sobre a vida de quem acompanha o envelhecer e o morrer do idoso e que continua vivo após seu falecimento, foram identificadas ações, como conversas com a finalidade de ajudá-los com o luto e a organização do local e de dinheiro para os rituais fúnebres no intuito de evitar problemas, além de transmissão patrimonial com o propósito de auxiliá-los na continuidade de suas vidas. Constataram-se, a quem acredita, cuidados com a reencarnação, como a ausência de dívidas com o propósito de garantir tranquilidade em uma próxima vida.

A morte pode ser um espaço de morrer, ou seja, ao se falar dela é que se abre a possibilidade de um processo de preparação de morte (Araújo \& Vieira, 2004). Cada época e cultura têm parâmetros diferentes do que é uma boa morte (Kovács, 2014). As pessoas têm desejos e expectativas diferentes, assim, é fundamental, para que se viva com qualidade a própria morte, falar sobre ela e informar pessoas próximas sobre desejos, levando a um planejamento final da existência, assim como os entrevistados fizeram. Não há como controlar ou saber se os profissionais, as famílias e amigos seguirão as orientações dadas, mas poder expressar as preferências individuais é o primeiro passo para que elas possam ser respeitadas.

\section{Considerações finais}

A compreensão dos acontecimentos não se esgota, uma vez que sempre será possível desvelar novos enunciados que tragam reflexões sobre o tema. A produção de conhecimento é considerada um processo contínuo.

A reflexão desenvolvida procurou contribuir para a diversificação de significados sobre o envelhecer e o morrer. Tentou-se ultrapassar a perspectiva tradicional de medo sobre esses processos, a partir do entendimento de como cada pessoa lida e compreende seu envelhecimento e sua finitude, que pode ou não ser permeado por sofrimento. Assim, este estudo buscou facilitar a desmistificação do tabu contemporâneo sobre a morte. Adentrar a singularidade dos idosos e apreender o sentido que cada um dá para a vida e para a morte contribui para a elaboração desse tema e promove um morrer de acordo com as vontades do indivíduo e, consequentemente, uma morte mais digna.

Um aspecto relevante no discurso dos participantes foi a relação com a família, os profissionais da saúde e de outras áreas, como a advogada, que possam ser convocados a lidar com a temática da morte. Foi frequente a dificuldade em escutar e acolher a demanda dos idosos de falar e pensar sobre a questão da finitude. Por meio das considerações desenvolvidas, há o intuito de trazer naturalidade ao tema para facilitar a reflexão sobre o viver e o morrer e contribuir para a melhora do acolhimento de pessoas que entrem em contato com a própria finitude, fomentando a qualidade da assistência prestada a essa população.

Foram identificadas diversas possibilidades que os entrevistados significaram como preparação para a morte em diferentes âmbitos, pois permearam questões financeiras, emocionais, sociais, corporais, materiais e espirituais. Verificou-se que o sentido das preparações para a morte foi na direção de um cuidar da vida. As realizações se mostraram como tentativas de garantir a melhor qualidade na existência, seja em relação à vida do próprio idoso até sua morte, ou de uma possível próxima vida, bem como sobre a existência de quem permanece vivo até e após a morte do idoso, como os familiares e amigos.

Fica evidente que, tão verdadeira quanto a expressão social de que "a única verdade da vida é a morte", é possível afirmar que "a única certeza da morte é a vida". Isso quer dizer que a morte convoca para o tempo do viver. Entrar em contato com a finitude viabiliza o encontro da possibilidade de uma vida digna de ser vivida para aquela pessoa naquele momento de sua existência. A manutenção do que faz sentido viver é um trabalho que deve ser atualizado a cada instante. Portanto é essencial falar sobre a morte e o morrer, pois é aberta, ao mesmo tempo, a possibilidade de falar sobre a vida e, assim, viver a melhor vida possível. 


\section{Preparation for death: phenomenological investigation on the experience of long-lived older adults}

Abstract:Aging is a worldwide phenomenon that gained prominence in recent decades. In this context, death appears as a complicated matter because it is a taboo in Western culture. In light of existential phenomenology, this project analyzed the experience of seniors over 80 who consider they have prepared for death. Several initiatives on their part permeating financial, emotional, social, corporal, material and spiritual issues have been verified. These initiatives were proven to be attempts to ensure the quality of the remainder of their life as well as the well being of their family and friends even after their passing. Thus, it is clear that "the only certainty of death is life", that is, getting in touch with finitude makes it possible to find the possibilities of life that make it worth living.

Keywords: aging, death, attitude to death, phenomenology, hermeneutics.

\section{Préparation à la mort : investigation phénoménologique d'après l'expérience de personnes âgées de longue durée}

Résumé : Le vieillissement de la population est un phénomène mondial qui a gagné en importance au cours des derniers décennies. La mort est devenue donc un questionnement difficile, car c'est un objet tabou dans la culture occidentale. À la lumière de la phénoménologie existentielle, ce projet vise à comprendre l'expérience de longévité des personnes âgées qui se sont préparées à la mort. Nous avons constaté diverses initiatives imprégnant des questions financières, émotionnelles, sociales, corporelles, matérielles et même spirituelles. La signification de ces préparatifs s'est révélée comme une prise en charge de la vie, en essayant de garantir une meilleure qualité de vie pour soi-même jusqu'à sa mort, ou pour ceux qui resteront en vie après cette mort. Ainsi, il est évident que "la seule certitude de la mort est la vie », car pour entrer en contact avec la finitude il faut viabiliser toutes les possibilités de vie dignes d'être vécues.

Mots-clés : vieillissement, mort, attitude face à la mort, phénoménologie, herméneutique.

\section{Preparación para la muerte: investigación fenomenológica sobre la experiencia de personas mayores longevas}

Resumen: El envejecimiento poblacional es un fenómeno mundial que adquirió gran importancia en las últimas décadas. En ese contexto, la muerte aparece como una cuestión difícil, ya que se trata de un tema tabú en la cultura occidental. Desde el punto de vista de la fenomenología existencial, este proyecto buscó comprender la experiencia de personas mayores longevas que consideran haberse preparado para la muerte. Se constataron diversas iniciativas que van desde cuestiones financieras, emocionales, sociales, corporales, materiales hasta espirituales. El sentido de esa preparación se reveló como un cuidar de la vida, pues se muestran como intentos de garantizar una mejor calidad para la existencia, sea en relación a su propia vida hasta la muerte, sea de quien sigue vivo hasta y después de la muerte de la persona mayor, como de familiares y amigos. De esta manera, se hace evidente que "la única certeza de la muerte es la vida", pues, el entrar en contacto con la finitud viabiliza el encuentro de posibilidades en relación a las vidas dignas de vivirlas.

Palabras clave: envejecimiento, muerte, actitud frente a la muerte, fenomenología, hermenéutica.

\section{Referências}

Andrade, M. A. R. (2012). Representação da morte: concepções a partir de experiências de vida de idosasusuárias do PSF. Revista Kairós, 15(4), 309-324. Recuperado de https://bit.ly/359hEuw

Araújo, P. V. R., \& Vieira, M. J. (2004). A questão da morte e do morrer. Revista Brasileira de Enfermagem, 57(3), 361-363. doi: 10.1590/S0034-71672004000300022

Ariès, P. (2012). História da morte no ocidente (ed. esp.). Rio de Janeiro, RJ: Saraiva. (Trabalho original publicado em 1977)

Ariès, P. (1989). O homem diante da morte (2a ed.). Rio de Janeiro: Francisco Alves. (Trabalho original publicado em 1977)
Barbieri, N. A., Goldfarb, D. C., Gotter, M. E. M., \& Peixeiro, M. H. (2009). Depressão e envelhecimento na contemporaneidade. Revista Kairós, 12(5), 54-79. Recuperado de https://bit.ly/35aip6k

Bosi, E. (2016). Memória e sociedade: lembranças dos velhos. São Paulo, SP: Companhia das Letras. (Trabalho original publicado em 1994)

Brasil. (2006). Atenção à saúde da pessoa idosa e envelhecimento. Brasília, DF: Ministério da Saúde. Recuperado de https://bit.ly/2Dy6pAp

Conselho Federal de Medicina. (2012). Resolução CFM $\mathrm{n}^{\circ} 1.995 / 2012$. Dispõe sobre as diretivas antecipadas de 
vontade dos pacientes. Diário Oficial Da União, (170), 269-270. Recuperado de https://bit.ly/3lVLUig

Casanova, M. A. (2006). Nada a caminho: impessoalidade, niilismo e técnica na obra de Martin Heidegger. Rio de Janeiro, RJ: Forense Universitária.

Combinato, D. S., \& Queiroz, M. D. S. (2006). Morte: uma visão psicossocial. Estudos de Psicologia, 11(2), 209-216. doi: 10.1590/S1413-294X2006000200010

Crippa, A., \& Gomes, I. (2014). Pedidos judiciais relacionados à interdição de idosos. Revista Kairós Gerontologia, 17(3), 329-342. Recuperado de https://bit.ly/2QZIUUY

Critelli, D. M. (2006). Analítica do sentido: uma aproximação e interpretação do real de orientação fenomenológica (2a ed.). São Paulo, SP: Brasiliense.

Elias, N. (2001). A solidão dos moribundos. Rio de Janeiro, RJ: Zahar. (Trabalho original publicado em 1982)

Feijoo, A. M. L. C. (2011). A existência para além do sujeito: a crise da subjetividade moderna e suas repercussões para a possibilidade de uma clínica psicológica com fundamentos fenomenológico-existenciais. Rio de Janeiro, RJ: Via Verita.

Feijoo, A. M. L. C., \& Dhein, C. F. (2014). Uma compreensão fenomenológico-hermenêutica das compulsões na atualidade. Fractal: Revista de Psicologia, 26(1), 165-178. doi: 10.1590/S1984-02922014000100013

Fornazari, S. A., \& Ferreira, R. E. R. (2010). Religiosidade/ espiritualidade em pacientes oncológicos: qualidade de vida e saúde. Psicologia: Teoria e Pesquisa, 26(2), 265-272. doi: 10.1590/S0102-37722010000200008

Franco, C. (2007). A crise criativa no morrer: a morte passa apressada na pós-modernidade. Revista Kairós, 10(1), 109-120. Recuperado de https://bit.ly/335eNjH

Franco, M. H. P. (2008). Luto em cuidados paliativos. In Conselho Regional de Medicina do Estado de São Paulo, Cuidado Paliativo (pp. 559-570). São Paulo, SP: Cremesp.

Giberti, G. M. (2018). A única certeza da morte é a vida: investigação fenomenológica sobre idosos que se preparam para a morte (Dissertação de mestrado). Universidade de São Paulo, São Paulo, SP.

Heidegger, M. (2012). Ser e tempo (F. Castilho Trad). Petrópolis, RJ: Vozes. (Trabalho original publicado em 1927)

Heidegger, M. (2002). A questão da técnica. In M. Heidegger, Ensaios e conferências (pp. 11-38). Rio de Janeiro, RJ: Vozes. (Trabalho original publicado em 1953)

Houaiss, A., \& Villar, M. S. (2009). Dicionário Houaiss da lingua portuguesa. Rio de Janeiro, RJ: Objetiva.

Instituto Brasileiro de Geografia e Estatística. (2008). Projeções da população do Brasil por sexo e idade 1980-2050, Revisão 2008. Rio de Janeiro, RJ: IBGE. Recuperado de https://bit.ly/2F9rr8Z

Junges, J. R., Cremonese, C., Oliveira, E. A., Souza, L. L., \& Backes, V. (2010). Reflexões legais e éticas sobre o final da vida: uma discussão sobre a ortotanásia. Revista Bioética, 18(2), 275-288. Recuperado de https://bit.ly/3n93MqO

Kovács, M. J. (1992). Morte e desenvolvimento humano. São Paulo, SP: Casa do Psicólogo.

Kovács, M. J. (2003a). Bioética nas questões da vida e da morte. Psicologia USP, 14(2), 115-167. doi: $10.1590 / \mathrm{s} 0103-65642003000200008$
Kovács, M. J. (2003b). Educação para a morte. São Paulo, SP: Casa do Psicólogo.

Kovács, M. J. (2014). A caminho da morte com dignidade no século XXI. Revista Bioética, 22(1), 94-104. doi: 10.1590/s1983-80422014000100011

Kübler-Ross, E. (2016). Sobre a morte e o morrer: o que os doentes terminais têm para ensinar a médicos, enfermeiros, religiosos e aos seus próprios pacientes (9a ed.). São Paulo, SP: WMF Martins Fontes. (Trabalho original publicado em 1981)

Lima, T. A. S., \& Menezes, T. M. O. (2011). Investigando a produção do conhecimento sobre a pessoa idosa longeva. Revista Brasileira de Enfermagem, 64(4), 751-759. doi: 10.1590/S0034-71672011000400019

Lourenço, T. M., Lenard, M. H., Kletemberg, D. F., Seima, M. D., Tallmann, Ana E. C., \& Neu, D. K. M. (2012). Capacidade funcional no idoso longevo: uma revisão integrativa. Revista Gaucha de Enfermagem, 33(2), 176-185. doi: 10.1590/S1983-14472012000200025

Martins, A. A. (2007). Consciência de finitude, sofrimento e espiritualidade. O Mundo Da Saúde, 31(2), 174-178. Recuperado de https://bit.ly/322i6c7

Minayo, M. C. S. (2017). Amostragem e saturação em pesquisa qualitativa: consensos e controvérsias. Revista Pesquisa Qualitativa, 5(7), 1-12. Recuperado de https://bit.ly/3i2Xoyf

Moreira-Almeida, A., Lotufo-Neto, F., \& Koenig, H. G. (2006). Religiousness and mental health: a review. Revista Brasileira de Psiquiatria, 28, 242-250. doi: 10.1590/S1516-44462006005000006

Nunes, M. I., \& Anjos, M. F. (2014). Diretivas antecipadas de vontade: benefícios, obstáculos e limites. Revista Bioética, 22(2), 241-51. doi http:// dx.doi.org/10.1590/1983-80422014222005.

Pessini, L. (2007). Distanásia. Até quando prolongar a vida? (2a ed.). São Paulo, SP: Loyola.

Reis, R. R. (2004). O outro fim para o Dasein: o conceito de nascimento na ontologia existencial. Natureza Humana, 6(1), 53-77. Recuperado de https://bit.ly/31NJi62

Sodelli, M. (2006). Aproximando sentidos: formação de professores, educação, drogas e ações redutoras de vulnerabilidade (Tese de doutorado). Pontifícia Universidade Católica, São Paulo, SP.

Szymanski, H. (2004). Entrevista reflexiva: um olhar psicológico sobre a entrevista em pesquisa. In L. R. Almeida, R. C. Al. R. Brandini, \& H. Szymanski (Orgs.), Entrevista na pesquisa em educação: a prática reflexiva (4a ed., pp. 9-64). Brasília, DF: Líber Livro.

Villasenor, R. L., \& Concone, M. H. V. B. (2012). A celebração da morte no imaginário popular mexicano. Revista Temática Kairós Gerontologia, 15(4), 37-47. Recuperado de https://bit.ly/2GAczkH

World Health Organization. (2015). World Report on Ageing and Heath. Geneva: WHO. Recuperado de https://bit.ly/3i5aDhJ

Recebido: 29/04/2020 Aprovado: 24/08/2020 